\title{
QS ENDO Real - A Study by the German Endometriosis Research Foundation (SEF) on the Reality of Care for Patients with Endometriosis in Germany, Austria and Switzerland \\ QS ENDO Real - Eine Studie der Stiftung Endometrioseforschung (SEF) zur Versorgungsrealität von Patientinnen mit Endometriose in Deutschland, Österreich und der Schweiz
}

(ㄷ) (1)

Authors

Felix Zeppernick ${ }^{1 *}$, Magdalena Zeppernick ${ }^{1}$, Elisabeth Janschek ${ }^{2}$, Monika Wölfler ${ }^{3}$, Sebastian Bornemann ${ }^{4}$, Laura Holtmann $^{4}$, Frank Oehmke ${ }^{1}$, Iris Brandes ${ }^{5}$, Chi Mi Scheible ${ }^{6}$, Darius Salehin ${ }^{6}$, Sigrid Vingerhagen Pethick ${ }^{7}$, Alexander Stephan Boosz ${ }^{8}$, Bernhard Krämer ${ }^{9}$, Martin Sillem ${ }^{10,11}$, Klaus Bühler ${ }^{12,13}$, Jörg Keckstein ${ }^{10}$, Karl Werner Schweppe ${ }^{10}$, Ivo Meinhold-Heerlein ${ }^{1}$, for the QS Endo Working Group of the Endometriosis Research Foundation (SEF) ${ }^{* *}$

Affiliations

1 UKGM, Zentrum für Frauenheilkunde Gießen, Gießen, Germany

2 LKH Villach, Villach, Austria

3 Frauenklinik der medizinischen Universität Graz, Graz, Austria

4 MMF GmbH, Dortmund, Germany

5 Institut für Epidemiologie, Sozialmedizin und Gesundheitssystemforschung, Medizinische Hochschule Hannover, Hannover, Germany

6 Johanniter GmbH; Evangelisches Krankenhaus Bethesda Mönchengladbach, Mönchengladbach, Germany

7 Drammen Hospital, Drammen, Norway

8 Städtisches Klinikum Karlsruhe, Karlsruhe, Germany

9 Universitätsfrauenklinik Tübingen, Tübingen, Germany

10 Vorstand Stiftung Endometriose-Forschung, Germany

11 Praxisklinik am Rosengarten, Mannheim, Germany

12 klin.-wissenschaftl. Endometriosezentrum der

Univ.-Kliniken des Saarlandes, Frauenärzte am Staden, Saarbrücken, Germany

13 Klinik für Frauenheilkunde und Fortpflanzungsmedizin Universitätsklinikum Jena, Jena, Germany

* These authors contributed equally to this publication.

** Members of the QS Endo Working Group who attended the Weissensee conferences of the SEF in 2016 and 2017: Dubravko Barisic, Alexander Boosz, Iris Brandes, Gerald Fischerlehner, Nannette Grübling, Elisabeth Janschek, Bernhard Krämer, Ivo Meinhold-Heerlein, Frank Oehmke, Peter Oppelt, Ralf Rothmund, Darius Salehin, Chi Mi Scheible, Miriam Schempershofe, Vanadin Seifert-Klauss, Omar Shebl, Sigrid Vingerhagen Pethick, Peter Widschwendter, Pauline Wimberger, Monika Wölfler, Felix Zeppernick, Magdalena Zeppernick.

\section{Key words}

endometriosis, quality assurance, quality of care,

care research

\section{Schlüsselwörter}

Endometriose, Qualitätssicherung, Versorgungsqualität, Versorgungsforschung

received 13.2.2019

revised 20.9.2019

accepted 23.11.2019

\section{Bibliography}

DOI https://doi.org/10.1055/a-1068-9260

Geburtsh Frauenheilk 2020; 80: 179-189 @ Georg Thieme

Verlag KG Stuttgart · New York I ISSN 0016-5751

\section{Correspondence}

Ivo Meinhold-Heerlein

Justus Liebig Universität Gießen Fachbereich Medizin,

Frauenklinik

Klinikstraße 33, 35392 Gießen, Germany

Ivo.Meinhold-Heerlein@gyn.med.uni-giessen.de

$\Theta$

Deutsche Version unter:

https://doi.org/10.1055/a-1068-9260

Supporting Information:

https://doi.org/10.1055/a-1068-9260 


\section{ABSTRACT}

Endometriosis affects a significant number of young premenopausal women. Quite apart from the medical challenges, endometriosis is a relevant burden for healthcare and social security systems. Standardized quality indicators for the treatment of endometriosis have not previously been systematically verified. The three-stage study QS ENDO was initiated to record and improve the reality and quality of care. One of its aims is to create quality indicators for the diagnosis and treatment of endometriosis. For the first stage of QS ENDO Real, letters were sent to all 1014 gynecological departments in the German-speaking area of Europe (the DACH region) which included a questionnaire as a means of surveying the current state of care. A total of 296 (29.2\%) of the centers which received the questionnaire participated in the survey. The subsequent evaluation of the completed questionnaires showed that the majority of patients with endometriosis (around $60 \%$, based on estimates from the data) are not treated in hospitals which have been certified by the SEF. The guidelines recommend the use of specific classification systems (rASRM, ENZIAN) but, depending on the level of care offered by the hospital, only around 44.4 to $66.4 \%$ of departments used the rASRM score and only $27 \%$ of hospitals used the ENZIAN classification system to describe deep-infiltrating endometriosis. When taking patients' medical history, some centers (6.6$17.9 \%$ ) considered questions about leading symptoms such as dyschezia, dysuria and dyspareunia to be unimportant. QS ENDO Real has made it possible, for the first time, to get an overview of the reality of care provided to patients with endometriosis in the German-speaking areas of Europe. The findings indicate that several of the measures recommended in international guidelines as the gold standard of care are only used to treat some of the patients. In this respect, more efforts will be needed to provide more advanced training. The approach used for treatment must be guideline-based, also in not-certified centers, to improve the quality of care in the treatment of patients with endometriosis.

\section{ZUSAMMENFASSUNG}

Endometriose betrifft einen großen Teil junger prämenopausaler Frauen und stellt neben den medizinischen Herausforderungen eine relevante Belastung für das Gesundheits- und Sozialsystem dar. Standardisierte Qualitätsindikatoren für die Behandlung der Endometriose wurden bisher nicht systematisch überprüft. Die dreistufige Studie QS ENDO wurde initiiert, um die Versorgungsrealität und -qualität zu erfassen und zu verbessern. Dabei sollen auch Qualitätsindikatoren für die Diagnostik und Therapie der Endometriose generiert werden. In der ersten Stufe QS ENDO Real wurden alle 1014 gynäkologischen Abteilungen im deutschsprachigen Raum (DACH-Region) angeschrieben und die aktuelle Versorgungssituation per Fragebogen ermittelt. An der Erhebung nahmen 296 (29,2\%) der angeschriebenen Zentren teil. Bei der Auswertung zeigt sich, dass ein Großteil der Endometriosepatientinnen (ca. $60 \%$ basierend auf geschätzten Angaben) nicht in von der SEF zertifizierten Kliniken behandelt wird. Die in den Leitlinien empfohlene Nutzung von Klassifizierungssystemen ( $r A S R M$, ENZIAN) wird in Bezug auf den rASRM-Score je nach Versorgungsstufe von 44,4 bis $66,4 \%$, für tief infiltrierende Endometriose (ENZIAN) sogar nur von ca. $27 \%$ der Kliniken angegeben. Bei der Anamneseerhebung werden Fragen nach den Leitsymptomen Dyschezie, Algurie und Dyspareunie von einem großen Anteil der Zentren (6,6-17,9\%) nicht als wichtig beurteilt. Mit QS ENDO Real ist es erstmalig gelungen, einen Überblick der Versorgungsrealität für Endometriosepatientinnen im deutschsprachigen Raum zu erhalten. Die Ergebnisse lassen darauf schließen, dass mehrere der in internationalen Leitlinien als Goldstandard empfohlenen Maßnahmen nur bei einem Teil der Patientinnen durchgeführt werden. Insofern sind weitere Anstrengungen bei der Fort- und Weiterbildung zu fordern. Gerade auch in den nicht zertifizierten Kliniken muss eine leitlinienorientierte Behandlung erfolgen, um die Versorgungsqualität bei der Behandlung von Endometriosepatientinnen zu verbessern.

\section{Introduction}

Endometriosis affects approximately $10-15 \%$ of premenopausal women [1,2]. Patients commonly suffer from cycle-related pain but also report non-cycle-related discomfort. Analgesics and even morphine use are very common, with some patients reporting that they are resistant to analgesics. Disorders of bladder and bowel function, pain during intercourse or infertility along with reduced fertility can significantly affect the quality of life of these young women [3]. The disease can become chronic, even when patients receive optimal treatment, meaning that some patients may require lifelong care. Despite intensive scientific efforts, the etiology and pathogenesis of the disease are still largely unknown. Moreover, valid biomarkers which could provide useful prognostic indications about the disease and potential responses to treatment are lacking [4]. There are some indications based on familial incidence which point to a possible genetic predisposition. En- zyme-related estrogen (estradiol) dominance accompanied by progestogen (progesterone) resistance is typical for the hormone dependence of endometriosis. There is considerable evidence that clinically, histologically and molecularly different diseases are being subsumed under the comprehensive label "endometriosis" [5]. According to the definition, all forms of the disease must have evidence of the presence of endometrium-like tissue outside the endometrial cavity. Certain forms of the disease even have the potential to become malignant, with endometriosis in certain affected patients associated with an increased risk of developing ovarian cancer [6-8].

Quite apart from the medical challenges of diagnosing and treating these women, many of whom are young with active personal and professional lives, endometriosis is a significant and relevant burden on society's healthcare and social security systems $[9,10]$. 
One of the main reasons for the disease's extensive and markedly adverse effect on patients' quality of life is the long delay in obtaining a correct diagnosis. The interval between the first onset of symptoms and the first visit to a doctor can be up to 3 years, followed by a further 7 years from the first consultation with a doctor until the diagnosis is made [11-13]. This dramatic lag time shows that endometriosis is not at the forefront of people's minds, irrespective of whether they are medical laymen or physicians. The delay in obtaining treatment goes beyond just the physical impairment, as it places heavy emotional and social burdens on affected patients. Burdens include the range of severe symptoms experienced in early adulthood and the possibility that the affected patient will be unable to have children with all the emotional and social consequences this entails [14]. It is not uncommon for frequent disease-related absences from work and periods in which the patient is unable to work to result in the patient losing her job. In addition, the symptoms can lead to partnership conflicts.

In addition to the lack of a diagnosis or the delay in obtaining a diagnosis, there is a question whether, despite the comprehensive setting up of endometriosis centers across German-speaking regions in Europe, endometriosis is being treated in accordance with the best currently existing standards - all of the above are reasons enough to investigate the reality of endometriosis care.

The positive findings following the analysis of care structures and quality assurance systems for ovarian cancer (QS-OVAR) carried out by the Ovary Commission of the Gynecological Oncology Working Group (AGO) prompted us to carry out a similar analysis for endometriosis [15].

QS-OVAR was able to show that even just a nationwide enquiry (in which any responses were entirely voluntary) about individual parameters as part of a quality assurance program led to an overall improvement in the quality of care provided to patients with ovarian cancer. While at the beginning of the study the implementation of treatment recommendations given in the guidelines varied quite considerably, implementation rates increased significantly over the course of the study [16]. QS-OVAR was also able to show that the structure and size of the treating hospital department did not have a significant impact on overall survival. Only the institution's participation in clinical trials was identified as a feature that significantly improved prognosis [15].

Other studies on ovarian cancer have also shown that structured further training of the medical staff involved in treating patients with ovarian cancer increased the probability that patients would receive the recommended treatment [17].

To date, standardized quality indicators for the treatment of endometriosis have neither been implemented nor systematically reviewed. This means that a survey investigating the quality of results cannot be effectively implemented [18]. A first retrospective analysis showed that a diagnostic and treatment concept based on the main presenting symptom was introduced as a single center concept in a special outpatient clinic for endometriosis and that this made it possible to provide a guideline-based diagnosis and treatment [19]. The aim of the QS ENDO survey is to identify indicators which can be used to measure the quality of treatment.

The QS ENDO Real aimed to gather data about the quality of endometriosis care in the DACH region (Germany, Austria, Swit- zerland) [20]. Three further steps are planned to comprehensively capture the quality of care and review the quality indicators for the diagnosis and treatment of endometriosis.

The second stage (QS ENDO Pilot) will ask questions about the actual treatment carried out in endometriosis centers offering secondary and tertiary care over a period of one month. In stage III (QS ENDO Study) the survey will be expanded to all hospitals offering endometriosis treatment in the $\mathrm{DACH}$ region. The fourth stage (QS ENDO Follow-up) aims to generate data for long-term prognosis by evaluating the follow-up data of patients including their pregnancy rates.

As the first program of its type, QS ENDO will provide a comprehensive understanding of the actual quality of care. We hope and expect that the implementation of this quality assurance program will contribute to improving the quality of care given to patients with endometriosis. It remains to be hoped that this will also be reflected by shorter times to obtaining a correct diagnosis as well as reducing the number of unnecessary surgical interventions, both of which would increase patients' overall quality of life.

\section{Methods}

\section{Sampled population}

In October 2016, a letter was sent to the senior consultants of all gynecological departments $(n=1014)$ in the DACH region. The letter also contained a two-page questionnaire which aimed to survey the quality of care provided to endometriosis patients (appendix). If we received no response, the questionnaire was re-sent in January 2017. All completed questionnaires returned by the end of February 2017 were included in the final evaluation.

\section{Questionnaire}

The contents of the questionnaire were developed by a panel consisting of 18 specialists from the scientific advisory board of the Endometriosis Research Foundation (Stiftung Endometrioseforschung, SEF) during a three-day conference in Weissensee in 2016 and agreed upon by the advisory board. The questionnaire was designed in such a manner that respondents were able to answer questions quickly and did not need to provide case-by-case analyses (pen-to-paper) as it was thought that this would lead to a high response rate and thus provide a largely representative picture. The target figure was a response rate of $10-20 \%$.

The questionnaire aimed to investigate both structural and content-related aspects.

In addition to asking about the department's size and structure, there were also questions about human resources management and development. Respondents were asked to estimate the number of patient contacts and surgical procedures performed. One group of questions specifically looked at the evaluation of specific symptoms and diagnostic steps (e.g., the evaluation of dysmenorrhea and the use of transvaginal ultrasound) as an effective and efficient way of obtaining patients' medical history and carrying out clinical examinations. Respondents were also asked about the use of existing classification systems such as the classification system of the American Society for Reproductive Medi- 
cine (rASRM score) [21] and the ENZIAN classification of deep-infiltrating endometriosis [22].

\section{Data analysis and reporting of results}

The survey data were initially subjected to descriptive analysis using SPSS. The departments offering endometriosis treatment were categorized according to their size and certification level for univariate analysis of the differences between centers. Centers were then divided into two groups: primary and secondary care providers and major providers of care. University clinics and hospitals, central hospitals, central hospitals with specialist departments, hospitals offering maximum care, specialist hospitals and hospitals offering tertiary care were grouped together as major providers of care. Primary and secondary care providers also included cottage hospitals and standard hospitals. A second evaluation was done which looked at whether the facility was an endometriosis center or not (certified/not certified). Certified centers included all centers certified as endometriosis centers by the SEF/EEL or the Endometriosis Association. The questionnaire did not differentiate between certification levels (level I: endometriosis center, level II: clinical endometriosis center, level III: clinical and scientific endometriosis center).

If responses to individual questions were missing, the overall population was adjusted for the respective subcategory. The largest differences with answers missing in 8 cases corresponded to an inaccuracy rate of only $2.7 \%$ for all participating centers. Given this low level of inaccuracy for data which was collected using a questionnaire, data were presented using adjusted overall population figures to optimize legibility rather than showing a "no information" bar.

\section{Results}

\section{Sampled population and response rate}

By the end of February 2017, a total of 296 completed questionnaires had been returned by the 1014 centers which had been sent letters. This equates to a response rate of $29.2 \%$. 257 study centers (86.8\%) in Germany, 27 centers (9.1\%) in Austria and 12 centers $(4.1 \%)$ in Switzerland participated in the study.

Of the clinics which participated in the study, the number of major care providers was approximately the same as the number of primary and secondary care providers; 153 "primary and secondary care providers" (51.7\%) and 143 "major care providers" (48.3\%) participated in the study. This ratio applied to the countries Germany (54.1 vs. $45.9 \%$ ) and Austria (48.1 vs. $51.9 \%$ ), while in Switzerland only one facility providing primary and secondary care and 11 major providers of care participated in the study (8.3 vs. $91.7 \%)$

A total of 38 hospitals (12.8\%) reported that their endometriosis center had been certified by the SEF. This means that the majority of study centers $(n=258,87.2 \%)$ which participated in the survey had not undergone an SEF certification process. Across all three countries, 19 of 32 university hospitals (59.4\%, country-specific range: $50-66.7 \%$ ) were certified by the SEF while in the other care institutions, 19 of 264 centers ( $7.2 \%$, country-specific range: $0-7.8 \%$ ) reported that they had been certified ( $>$ Fig. 1 ).
In the overwhelming majority of returned questionnaires, all subsections were completed. A few participants did not tick any of the boxes in individual subsections. This means that for a few subsections the total number of centers differs from the total sample of 296 participating centers. The largest deviation when calculating percentages pertained to non-responses in 8 cases, in which case the total population used for calculations was 288 centers. This corresponds to an inaccuracy rate, in the sense of variance, of just under $2.7 \%$ of all participating centers.

\section{Structural requirements and cooperation partners of the study centers}

While most centers (> 70\%) reported an interdisciplinary cooperation with the medical specialties Surgery, Urology, Pain Management, Pathology, and Radiology (> 70\%), only a few facilities had the opportunity to directly cooperate with specialties Rehabilitation, Psychosomatics, and Reproductive Medicine ( $\triangleright$ Fig.2). When we evaluated the major providers of care, all 143 study centers $(100 \%)$ reported that they cooperated with the Surgical Department. The same applied to almost all of the primary and secondary care providers (151 out of $153,98.7 \%$ ). 138 out of 143 (96.5\%) major care providers reported cooperating with a pathology department and 141 (98.6\%) reported cooperating with a radiology department with CT/MRI compared to 124 (81.0\%) and 139 (90.8\%), respectively, of primary and secondary care providers. While 139 (97.2\%) of the major care providers had the opportunity to cooperate with a Pain Management Department and 136 (95.1\%) cooperated with a Urology Department, the equivalent figures for primary and secondary care providers were 129 (84.3\%) and 107 (69.9\%), respectively.

$117(81.8 \%)$ and 78 (54.5\%), respectively, of the major care providers reported that they cooperated with a department for psychosomatics or reproductive medicine; the respective figures for the primary and secondary care providers were 82 (53.6\%) and $43(28.1 \%)$. While $79(55.2 \%)$ of the major care providers stated that they cooperated with a rehabilitation clinic, only 37 (24.2\%) of the primary and secondary care providers did. However, it is important to note in this context that there are countryspecific differences. While endometriosis-specific rehabilitation measures are offered as part of follow-up care and treatment in both Germany and Switzerland, in Austria, patients may only apply for rehabilitation through their GP, and endometriosis-specific rehabilitation is not applied for.

Almost all institutions had the option that patients could be examined on an outpatient basis; the figure for major care providers was 134 out of 143 study centers (93.7\%) and 139 out of 152 for primary and secondary care providers (91.4\%). 72 major care providers $(50.3 \%)$ had special endometriosis drop-in sessions while only 37 of the primary and secondary care centers did (24.3\%).

\section{Number of estimated procedures, types of surgical access, classification systems}

As regards the estimated number of patients with histologically confirmed endometriosis, 272 of the centers reported a total number of 23445 diagnoses.

After the estimated figures were interpolated (product of the arithmetic means of the number of diagnoses and the number of 


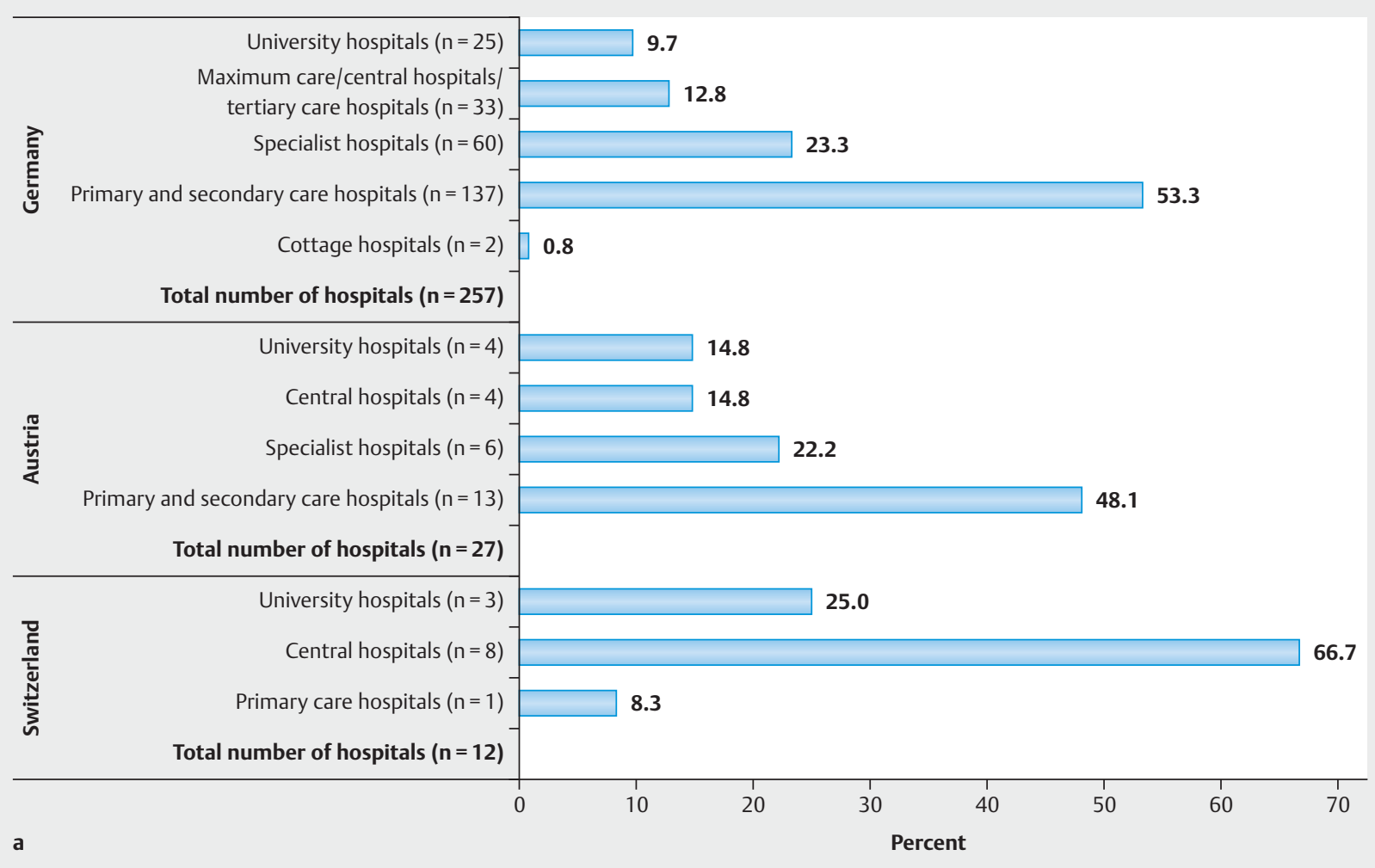

a

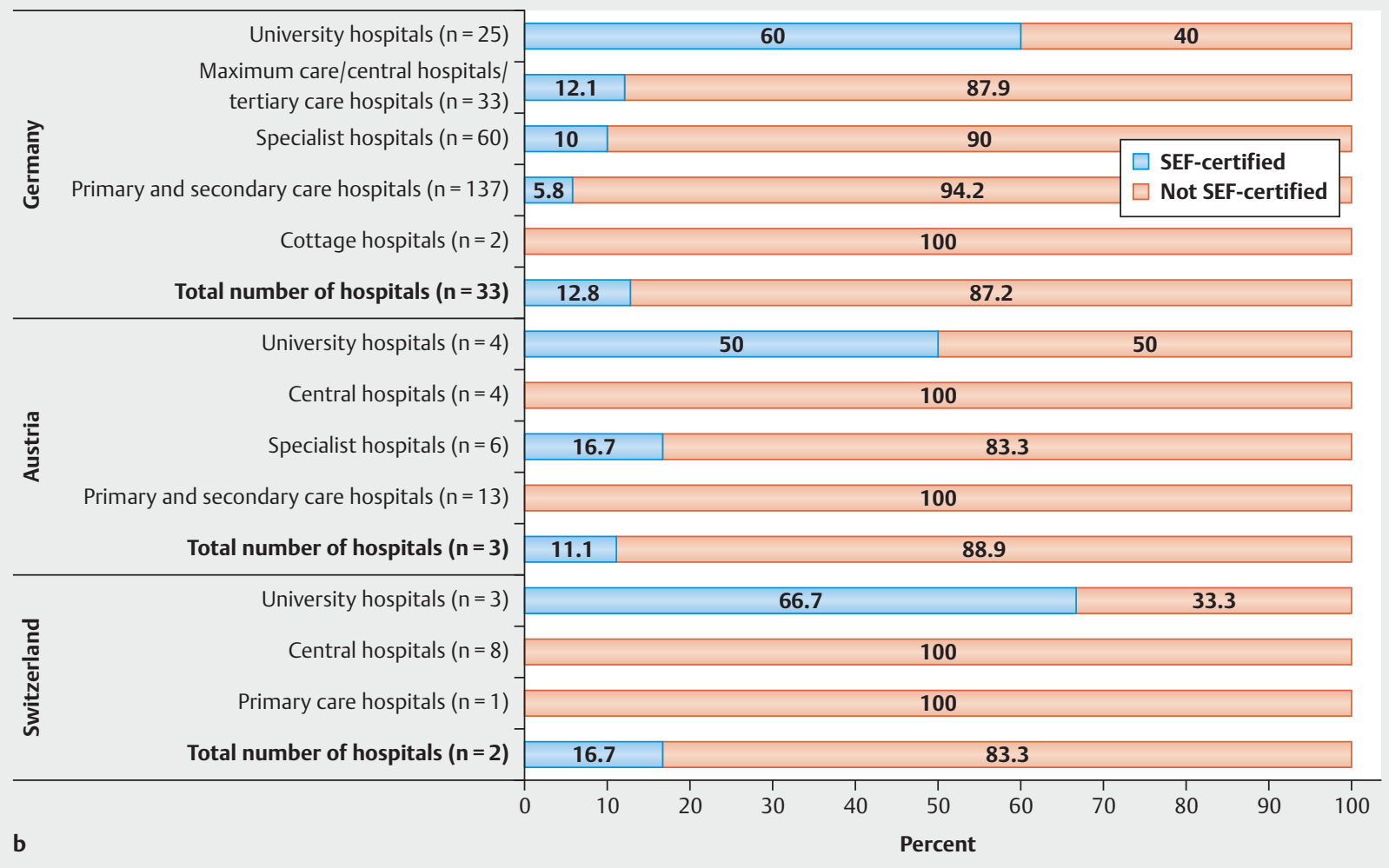

$\mathrm{n}=296$ participating centers, of which $38(12.8 \%)$ are SEF-certified

- Fig. 1 Country-specific overview of participating hospitals according to the level of care they provide (a) and percentage of facilities with SEF certification (b). 


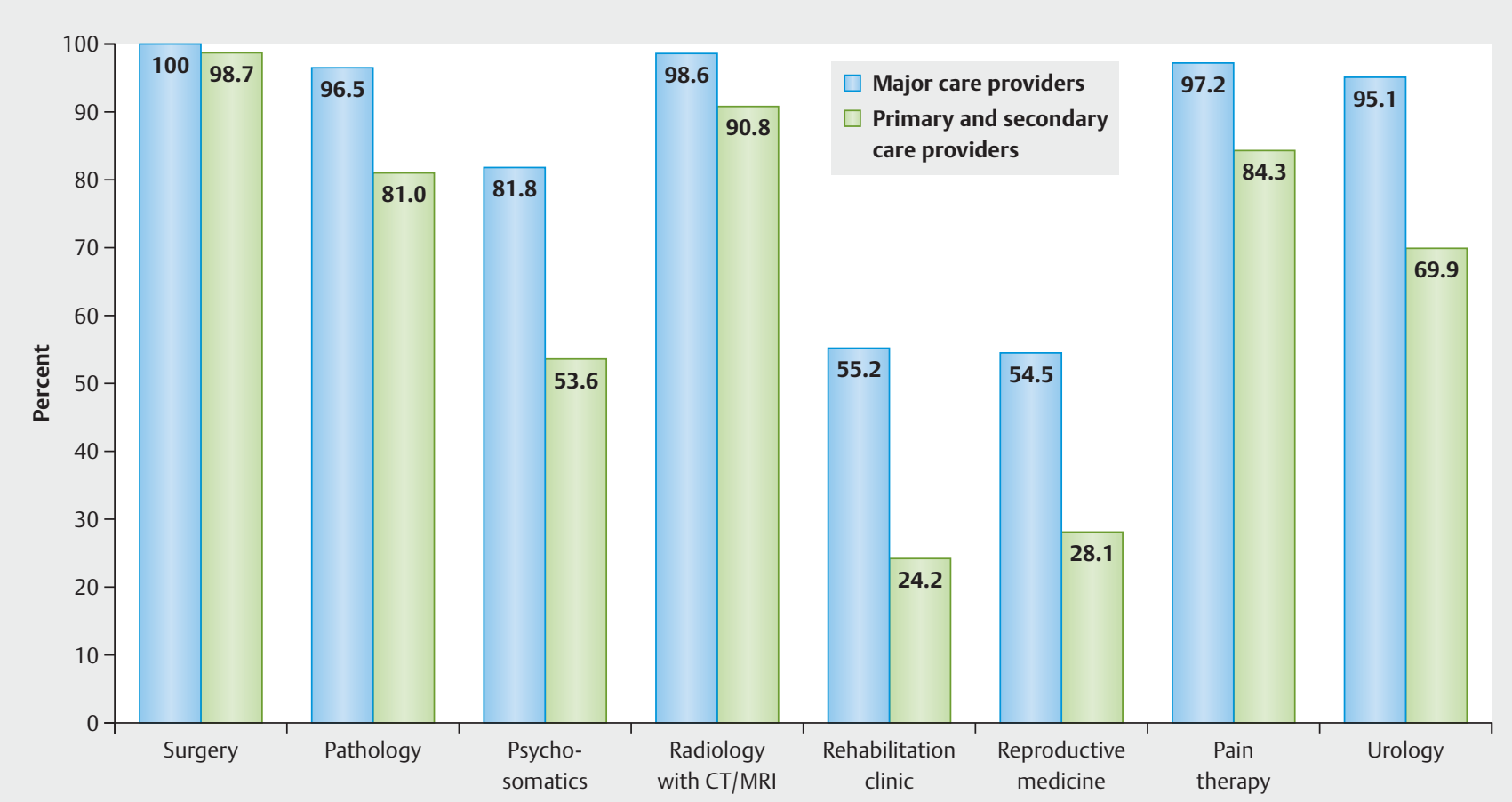

n= 296 centers, of which 143 are major care providers and 153 are providers of primary and secondary care

- Fig. 2 Opportunities to cooperate with other medical specialties according to the facility's level of care, in percent.

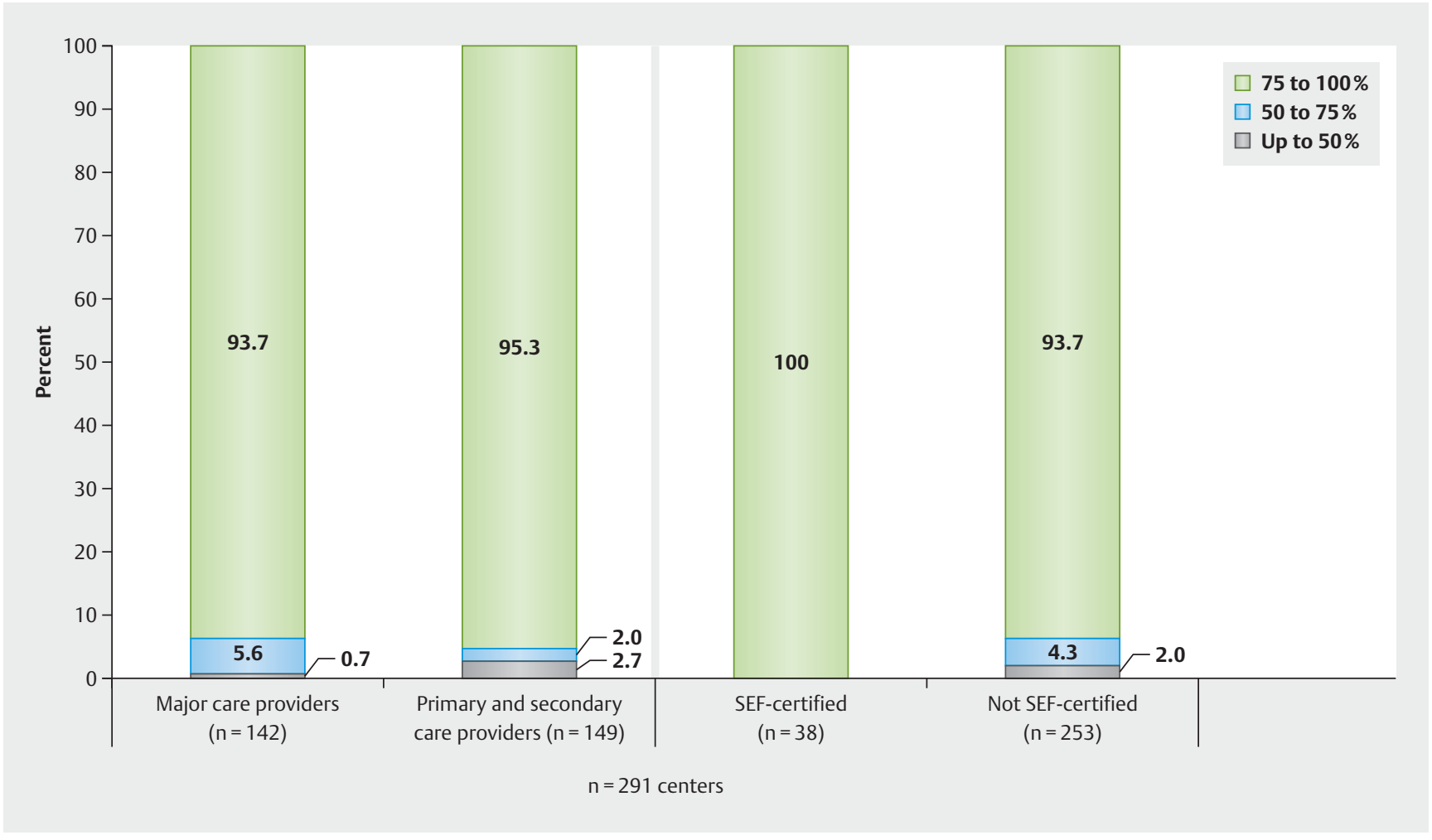

- Fig. 3 Percentage of laparoscopic procedures differentiated according to the level of care and the certification status of the respective institution, using a questionnaire-based survey of the current status of care. 
study centers), we were able to conclude that $39.8 \%(n=9320)$ of patients with histologically confirmed endometriosis were treated annually in SEF-certified endometriosis centers while $60.2 \%$ of patients ( $n=14136$ ) were operated on in not-certified centers.

In most institutions, more than $75 \%$ of surgical procedures were carried out using a laparoscopic approach (133 of 142 major care centers [93.7\%], and 142 of 149 primary and secondary care centers [95.3\%]). Accordingly, 9 out of 142 major care providers (6.3\%) and 7 of 149 primary and secondary care providers (4.7\%) stated that the percentage of laparoscopic operations performed in their institution was less than 75\%. Five of 291 centers (1.7\%) reported that the percentage of laparoscopic operations carried out in their facility was less than $50 \%$. All 16 study facilities (5.5\%) which reported less than $75 \%$ of laparoscopic surgeries did not have a certified endometriosis center ( $\triangleright$ Fig. 3 ).

256 of 290 study centers (88.3\%) rated the current endometriosis guideline as helpful or very helpful. 28 study centers (9.7\%) assessed the importance of the guideline as neutral. Six study centers $(2.1 \%)$ rated the guideline as not very helpful or stated that they were unaware of the guideline.

The classification system of the American Society for Reproductive Medicine ( $\mathrm{rASRM}$ ) and the system of the Endometriosis Research Foundation (SEF) to describe deep-infiltrating endometriosis (ENZIAN) were the most commonly used systems used to classify endometriosis into different stages. Of the 143 major providers of care, 95 centers (66.4\%) used the rASRM score, 47 (32.9\%) used the ENZIAN classification and 31 study centers (21.7\%) only described findings without classifying them. The corresponding figures for the primary and secondary care providers were 68 (44.4\%), $32(20.9 \%)$ and 63 (41.2\%), respectively, out of 153 study centers ( $\vee$ Fig. 4). All 94 of the 296 clinics (31.8\%) which stated that they only reported findings descriptively did not have a certified endometriosis center.

Very few centers used both the rASRM and the ENZIAN classification system as recommended in the guideline. 31 of 143 major care providers $(21.7 \%)$ and 14 out of 153 primary and secondary care providers (9.2\%) stated that they used both concurrently. Even among the SEF-certified endometriosis centers, only 19 of 38 departments $(50.0 \%)$ reported a concurrent use of both systems. The figure for not-SEF-certified centers was 26 out of 258 departments (10.1\%) (> Fig. 4 b).

281 of 288 study centers (97.6\%) reported taking biopsies to histologically confirm a diagnosis of endometriosis. Seven out of 288 study centers (2.4\%) did not regularly carry out such biopsies, of which 4 were major providers of care and 3 were primary and secondary care providers. All clinics which did not carry out regular histological confirmation did not have a certified endometriosis center.

\section{Evaluation of symptoms, questions about patients' medical history and steps to diagnosis}

As part of the process of taking patients' medical history and making a differential diagnosis, asking questions about dysmenorrhea was considered very important by 221 out of 287 centers (77.0\%) and rated as important by 64 (22.3\%), with 2 centers $(0.7 \%)$ evaluating it as neutral. Asking about pelvic pain $(n=286)$ was considered to be very important by 179 centers (62.6\%), as important by 98 (34.3\%) and as neutral or not very important by 9 centers (3.1\%). 36 of the 38 SEF-certified endometriosis centers answered the subsection on questions asked to patients when taking their medical history and rated asking patients about dysmenorrhea and pelvic pain at least as important. 34 of 36 SEF-certified endometriosis centers (94.4\%) and 187 of 251 not-certified study centers (74.5\%) considered asking about dysmenorrhea as very important ( $>$ Fig. 5). Asking about dyschezia was rated as neutral or not very important by 28 centers (9.8\%); asking about dysuria was rated as neutral or not very important by 51 centers (18.0\%), and asking about positional dyspareunia was rated as neutral or not very important by 19 (6.6\%) centers. Only study centers which had no certified endometriosis centers rated all three criteria as "not very important". Asking about dysuria was considered to be neutral by 3 (8.3\%) SEF-certified centers and asking about positional dyspareunia was rated as neutral by $1(2.8 \%)$ SEF-certified center.

Almost all of the study centers considered speculum examination of the posterior vaginal vault, bimanual palpation and transvaginal ultrasound during clinical examination as desirable or even essential ( $\triangleright$ Fig. 6). 267 study centers (92.7\%) considered speculum examination of the posterior vaginal vault to be essential, 268 centers $(93.1 \%)$ considered bimanual palpation and 262 study centers $(91.0 \%)$ considered transvaginal ultrasound to be essential. Transvaginal ultrasound was the only method of examination rated by all 36 responding SEF-certified centers (100\%) as essential, an opinion which was shared by 226 (89.7\%) not-certified study centers; a further $26(9.0 \%)$ considered transvaginal ultrasound to be desirable or were neutral.

Rectal examination was considered essential by 189 participating centers (65.6\%) and classified as desirable by a further 86 (29.9\%). 13 study centers (4.5\%), one of which was an SEF-certified endometriosis center, were neutral about the importance of rectal examinations. Kidney ultrasound examinations were classified as essential by 143 study centers (49.7\%) and as desirable by a further 115 departments (39.9\%). 23 study centers (8.0\%) were neutral about the importance of kidney ultrasound examinations, 2 of which were SEF-certified endometriosis centers, and 7 (2,4\%) not-certified study centers considered the examination as not very important.

\section{Discussion}

The quality assurance program QS ENDO was launched to record the actual quality of endometriosis care in the DACH region (Germany, Austria, Switzerland). The project is the first to provide a greater understanding of the care structures and actual quality of care in these countries.

QS ENDO Real obtained information from almost one third of all gynecological departments in the DACH region. It can be safely assumed that the high response rate was also due to the planned low-threshold opportunity to participate in the survey. This high response rate must be placed against the precision of the reported data as the data generally involved estimates. It is important to critically note that certain aspects may be both over- and under-estimated. However, one of the concerns of QS Endo Real was also to make the study known to gynecological departments 


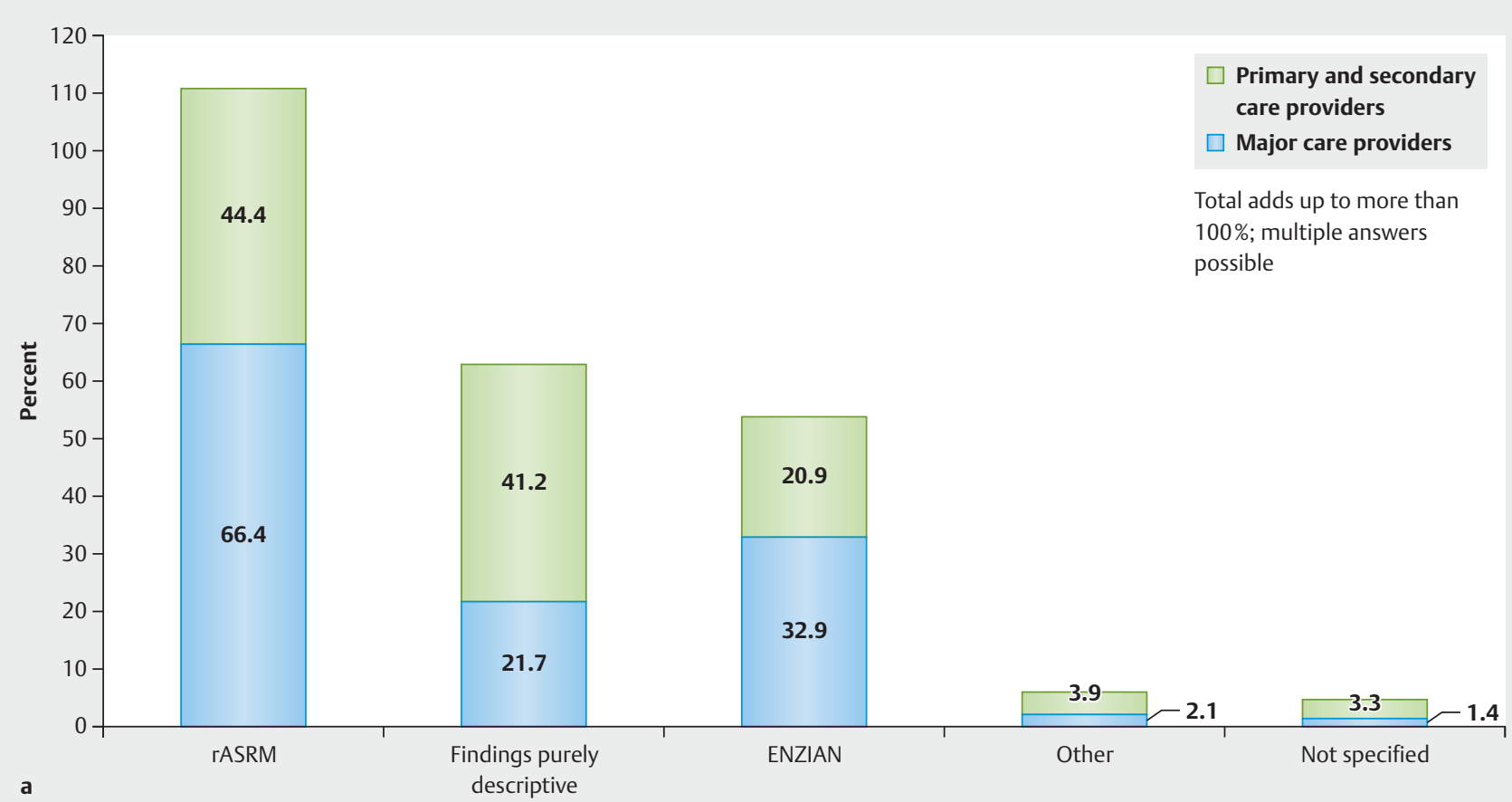

a

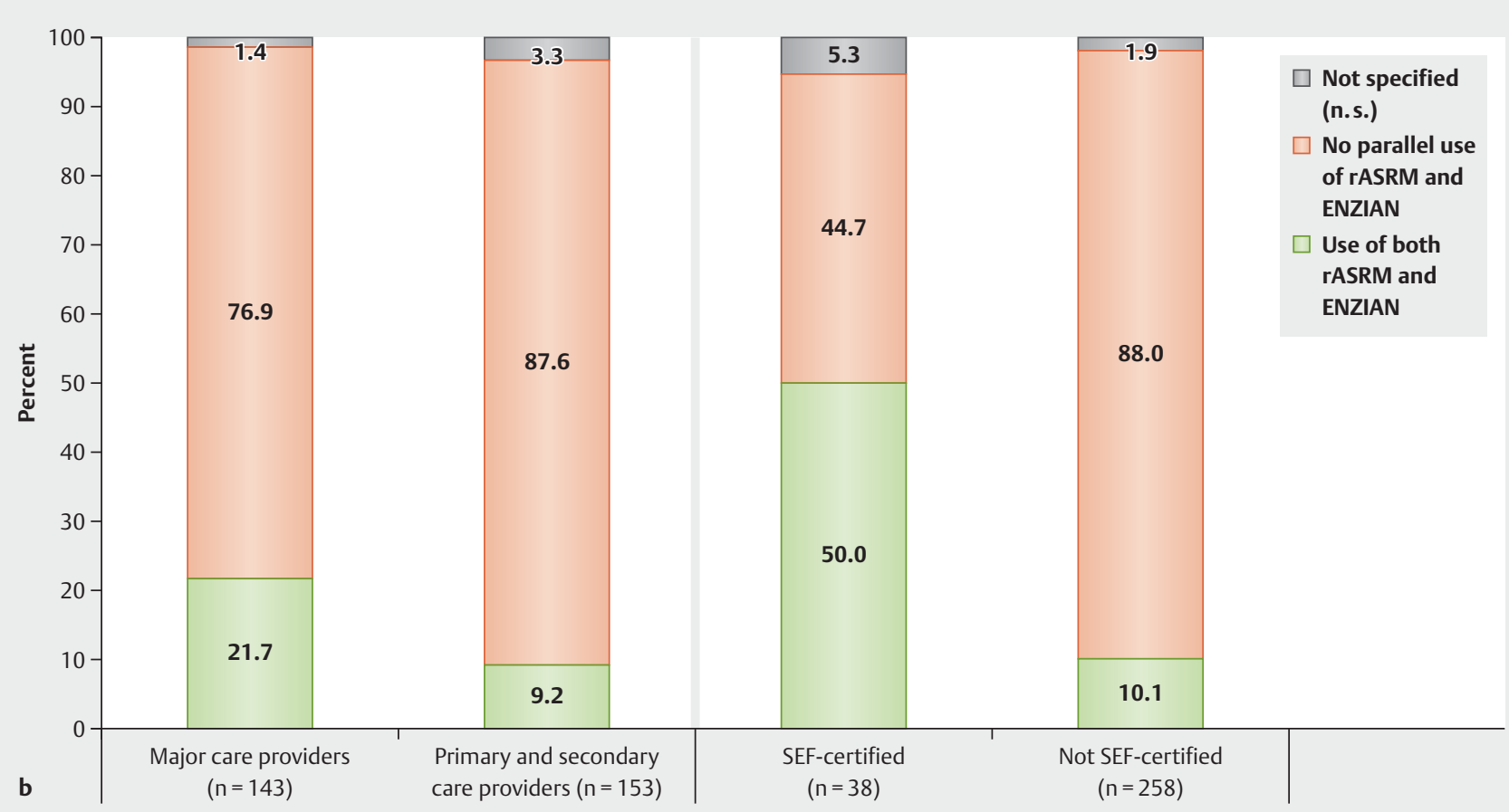

$\mathrm{n}=296$ centers, including 7 centers with no information provided

Fig. 4 Classification systems used to classify surgical endometriosis findings (a) and incidence of the parallel use of rASRM and ENZIAN classification systems (b), according to a questionnaire-based survey of the current status of care. 


\begin{tabular}{|c|c|c|c|c|}
\hline & Very important & Important & Neutral & $\begin{array}{l}\text { Not very } \\
\text { important }\end{array}$ \\
\hline $\begin{array}{l}\text { Pelvic pain } \\
(n=286)\end{array}$ & $\begin{array}{c}62.6 \\
(86.1 / 59.2)\end{array}$ & $\begin{array}{c}34.3 \\
(13.9 / 37.2)\end{array}$ & $\begin{array}{c}2.1 \\
(0.0 / 2.4)\end{array}$ & $\begin{array}{c}1.0 \\
(0.0 / 1.2)\end{array}$ \\
\hline $\begin{array}{l}\text { Dysmenorrhea } \\
(n=287)\end{array}$ & $\begin{array}{c}77.0 \\
(94.4 / 74.5)\end{array}$ & $\begin{array}{c}22.3 \\
(5.6 / 24.7)\end{array}$ & $\begin{array}{c}0.7 \\
(0.0 / 0.8)\end{array}$ & $\begin{array}{c}0.0 \\
(0.0 / 0.0)\end{array}$ \\
\hline $\begin{array}{l}\text { Dyschezia } \\
(n=285)\end{array}$ & $\begin{array}{c}54.0 \\
(88.9 / 49.0)\end{array}$ & $\begin{array}{c}36.1 \\
(11.1 / 39.8)\end{array}$ & $\begin{array}{c}8.4 \\
(0.0 / 9.6)\end{array}$ & $\begin{array}{c}1.4 \\
(0.0 / 1.6)\end{array}$ \\
\hline $\begin{array}{l}\text { Dysuria } \\
(n=284)\end{array}$ & $\begin{array}{c}40.5 \\
(69.4 / 36.3)\end{array}$ & $\begin{array}{c}41.5 \\
(22.2 / 44.4)\end{array}$ & $\begin{array}{c}16.5 \\
(8.3 / 17.7)\end{array}$ & $\begin{array}{c}1.4 \\
(0.0 / 1.6)\end{array}$ \\
\hline $\begin{array}{l}\text { Positional dyspareunia } \\
(n=286)\end{array}$ & $\begin{array}{c}57.0 \\
(75.0 / 54.4)\end{array}$ & $\begin{array}{c}36.4 \\
(22.2 / 38.4)\end{array}$ & $\begin{array}{c}4.9 \\
(2.8 / 5.2)\end{array}$ & $\begin{array}{c}1.7 \\
(0.0 / 2.0)\end{array}$ \\
\hline
\end{tabular}

All data are given in percent; numbers in black: percentage out of the total number of surveyed departments; in brackets: SEF-certified and not SEF-certified centers; none of the centers selected the option „not important".

- Fig. 5 Assessment about the importance of individual questions on patients' medical history, in percent (overall and according to the facility's certification status).

\begin{tabular}{|l|c|c|c|c|}
\hline & Essential & Desirable & Neutral & $\begin{array}{c}\text { Not very } \\
\text { important }\end{array}$ \\
\hline $\begin{array}{l}\text { Speculum examination } \\
\text { of the vaginal vault }\end{array}$ & $\begin{array}{c}92.7 \\
(91.7 / 92.9)\end{array}$ & $\begin{array}{c}6.9 \\
(8.3 / 6.7)\end{array}$ & $\begin{array}{c}0.3 \\
(0.0 / 0.4)\end{array}$ & $\begin{array}{c}0.0 \\
(0.0 / 0.0)\end{array}$ \\
\hline Bimanual palpation & 93.1 & 5.9 & 0.7 & 0.3 \\
\hline Rectal examination & $(97.2 / 92.5)$ & $(2.8 / 6.3)$ & $(0.0 / 0.8)$ & $(0.0 / 0.4)$ \\
\hline TVU (transvaginal & 65.6 & 29.9 & 4.5 & 0.0 \\
\hline ultrasound) & $(66.7 / 65.5)$ & $(30.6 / 29.8)$ & $(2.8 / 4.8)$ & $(0.0 / 0.0)$ \\
\hline Kidney ultrasound & 91.0 & 8.7 & 0.3 & 0.0 \\
\hline & $(100.0 / 89.7)$ & $(0.0 / 9.9)$ & $(0.0 / 0.4)$ & $(0.0 / 0.0)$ \\
\hline
\end{tabular}

All data are given in percent; numbers in black: percentage out of the total number of surveyed departments; in brackets: SEF-certified and not SEF-certified centers; none of the centers selected the option „not required“.

$n=288$ centers

Dig. 6 Assessment about the importance of different examinations, in percent (overall and according to the facility's certification status).

in order to encourage them to participate in the subsequent stages of the project. These subsequent stages, QS ENDO Pilot and QS ENDO Study, will be based on an analysis of individual patient files and will provide a well-founded and differentiated picture of the actual quality of care.

The percentage of participating institutions, which was just under $30 \%$, has already provided valuable information in this first stage of the study about the level of importance accorded to different parameters. The realization that the majority of patients are not being treated in certified endometriosis centers is important with regard to potential future efforts to improve the quality of treatment. This means that additional further training on endometriosis care must not be limited to certification measures. Instead, not-certified centers must be offered opportunities to im- prove their qualifications, even if they currently do not wish or are not able to take part in a certification process. Because of the onesided focus on certification measures, potential improvements in certification conditions by the Endometriosis Research Foundation and the Endometriosis Association will only reach a fraction of treated patients if $62 \%$ of patients are treated in facilities which have not undergone certification.

The data also show that the lack of interdisciplinary cooperation and the omission of different medical specialties results in suboptimal treatment modalities. Creating networks, identifying opportunities for cooperation, and implementing treatment paths should remedy some of these deficits. In view of the oftcited lack of cooperation with psychosomatics, rehabilitation medicine and reproductive medicine departments, it is evident 
that the current levels of care still do not cover important aspects involved in a comprehensive holistic treatment of patients and their needs. The next stages of the QS ENDO will show to what extent interdisciplinary treatment (which experts consider to be important) plays a role in patients' quality of life. The evaluation of the data obtained from QS ENDO Follow-up will be particularly interesting in this context, as these data will include information about the parameters "pregnancy rates", "control of symptoms", "compliance" and "quality of life".

Several of the most important manifestations of endometriosis (peritoneal, ovarian and deep-infiltrating) often present concurrently, resulting in differences in the symptoms experienced by individual patients. The SEF recommends the concurrent use of both classification systems, the rASRM system (for peritoneal and ovarian endometriosis) and the ENZIAN system (for deep-infiltrating and extragenital endometriosis) to classify the disease into its different stages, objectify it and make it comparable. A remarkable finding of our investigation was that only $52.8 \%$ of SEF-certified centers and fewer than $25 \%$ of hospitals providing major care reported using both classification systems concurrently and documenting their staging. If, therefore, around half of all certified centers do not record and classify the full extent of disease, we can only guess at the size of the overall deficits in this area. In the second stage of the study (QS ENDO Pilot) it will become clear whether the estimates provided by the heads of departments correspond to reality and how often both classification systems are really used in parallel. If the views expressed by heads of departments do not tally with the modalities for classifying and documenting disease actually used in the departments, then the procedures within the hospital may need to be standardized. It is probable that the required documentation was not carried out for the majority of patients. Documenting the extent of disease is, however, a central precondition to be able to measure and compare future treatments and their efficacy.

This discrepancy is very important, not least with regard to the evaluation of questions about patients' medical history and the methods used for clinical examination.

Asking patients about dyschezia, dysuria and dyspareunia was considered as neutral or not very important by approximately $10 \%$ of centers. This suggests that these questions are not asked when taking patients' medical history. But these are demonstrably important aspects which play a crucial role, particularly with regard to the quality of life of affected patients, many of whom are still quite young [23]. It could be speculated that improvements in these symptoms are not recognized as a treatment goal because the symptoms as such are not considered important and no questions are asked about them.

Because endometriosis is often present in the vicinity of the ureters and the bladder, this can lead to obstruction of the urinary flow, resulting in urinary stasis and ultimately hydronephrosis [24]. It is known that even if symptoms are not present, complete loss of kidney function can occur if urinary stasis is recognized too late [25]. Given these facts, the assessment by $10.4 \%$ of participants and even by $5.6 \%$ of certified centers of kidney ultrasound examinations as neutral or even not very important is a serious cause for alarm. If the additional $39.9 \%$ of centers which considered kidney ultrasound examinations as desirable only carry out these examinations occasionally, then the majority of urinary flow disorders will remain undetected and may only be found too late or intraoperatively, when it is not possible to inform and discuss with patients about potentially necessary measures which need to be initiated.

Deep-infiltrating endometriosis is often located in the rectovaginal space and can affect sexual intercourse, bowel function and even cause ileus. Although the overwhelming majority of all centers considered rectal examinations to be useful, nevertheless $4.5 \%$ of participating centers evaluated rectal examination of patients with endometriosis as "neutral". It is possible that deep-infiltrating endometriosis of the bowel requiring surgical correction and bowel resection may be missed if no rectal or rectovaginal examination is carried out. In such cases, appropriate preparations for potentially necessary interdisciplinary surgery or - if the necessary infrastructure is missing - referral to an appropriately qualified endometriosis center will not be done. Potential consequences can include aborted surgical procedures followed by additional surgery with all its medical and socioeconomic repercussions and the risk of additional morbidity for the patient.

The data was based on assessments given by experienced senior consultants working in centers which participated in QS ENDO Real and suggests that many measures recommended as the gold standard of treatment in national and international guidelines are not being implemented in the DACH region. Assuming that the participating centers are institutions which at least engage with the clinical picture and symptoms of endometriosis and are involved in promoting the best possible treatment, then the percentage of centers implementing recommended measures in the other $2 / 3$ of departments is likely to be considerably lower.

\section{Outlook}

Collecting valid data based on the records of individual patients in the second and third stages of the survey, QS ENDO Pilot and QS ENDO Study, should be very instructive. QS ENDO Pilot will be carried out in clinical (level II) and clinical and scientific (level III) centers certified by the Endometriosis Research Foundation/EEL and the Endometriosis Association. A complete collection of data from more than 400 patients has already been carried out. QS ENDO Pilot is a pilot study which aims to test the practicability of the online documentation system and generate quality indicators for the diagnosis and treatment of endometriosis. In addition, QS ENDO Pilot will provide information on whether certified centers really document the parameters required during certification and whether the patients attending these centers actually receive what is considered the best diagnostic workup and treatment based on the current state of scientific knowledge.

Ultimately, the QS ENDO Study will allow a statement to be made about the quality of care currently provided to endometriosis patients in the DACH region. Given the fact that the majority of all patients are being treated in not-certified centers, these data will provide a starting point to demonstrate the strengths but also the potential deficits of treatment and to develop and introduce measures to improve the quality of care. For a disease which affects such a huge number of young women, it is about time! 


\section{Appendix}

The questionnaire for the QS ENDO Real is available online in German: https://doi.org/10.1055/a-1068-9260

Acknowledgements

We would like to thank Prof. J. Pfisterer and Prof. A. du Bois for their support in developing the structural and scientific concept of QS ENDO. We would also like to thank Ms. A. Kubus and Ms. D. Söffge, both representatives of the Endometriosis Association, who provided valuable suggestions. We would like to thank all participating centers for their strong commitment and robust participation.

\section{Conflict of Interest}

No conflicts of interest reported. Several authors are leaders of SEFcertified Endometriosis centers. Klaus Bühler, Karl-Werner Schweppe and Martin Sillem are members of the SEF board.

\section{References}

[1] Burney RO, Giudice LC. Pathogenesis and pathophysiology of endometriosis. Fertil Steril 2012; 98: 511-519. doi:10.1016/j.fertnstert.2012. 06.029

[2] Mowers EL, Lim CS, Skinner B et al. Prevalence of endometriosis during abdominal or laparoscopic hysterectomy for chronic pelvic pain. Obstet Gynecol 2016; 127: 1045-1053. doi:10.1097/AOG.0000000000001422

[3] De Graaff AA, D'Hooghe TM, Dunselman GA] et al. The significant effect of endometriosis on physical, mental and social wellbeing: Results from an international cross-sectional survey. Hum Reprod 2013; 28: 26772685. doi:10.1093/humrep/det284

[4] Burghaus S, Fehm T, Fasching PA et al. The International Endometriosis Evaluation Program (IEEP Study) - A Systematic Study for Physicians, Researchers and Patients. Geburtsh Frauenheilk 2016; 76: 875-881. doi:10.1055/s-0042-106895

[5] Anglesio MS, Papadopoulos N, Ayhan A. Cancer-Associated Mutations in Endometriosis without Cancer. N Engl J Med 2017; 376: 1835-1848. doi:10.1056/NEJMoa1614814

[6] Pearce CL, Templeman C, Rossing MA et al. Association between endometriosis and risk of histological subtypes of ovarian cancer: A pooled analysis of case-control studies. Lancet Oncol 2012; 13: 385-394. doi:10.1016/S1470-2045(11)70404-1

[7] Grandi G, Toss A, Cortesi L et al. The Association between Endometriomas and Ovarian Cancer: Preventive Effect of Inhibiting Ovulation and Menstruation during Reproductive Life. Biomed Res Int 2015; 6: 1-10. doi:10.1155/2015/751571

[8] Krawczyk N, Banys-Paluchowski M, Schmidt D et al. Endometriosis-associated Malignancy. Geburtsh Frauenheilk 2016; 76: 176-181. doi:10.1055/s-0035-1558239

[9] Ulrich U, Buchweitz O, Greb R et al. National German Guideline (S2K). Guideline for Diagnosis and Treatment of Endometriosis, AWMF Registry No. 015-045. Geburtsh Frauenheilk 2014; 74: 1104-1118. doi:10.1055/ s-0034-1383187
[10] Simoens S, Dunselman G, Dirksen C et al. The burden of endometriosis: Costs and quality of life of women with endometriosis and treated in referral centres. Hum Reprod 2012; 27: 1292-1299. doi:10.1093/humrep/ des073

[11] Nnoaham KE, Hummelshoj L, Webster P et al. Impact of endometriosis on quality of life and work productivity: A multicenter study across ten countries. Fertil Steril 2011; 96: 366-373. doi:10.1016/j.fertnstert. 2011.05.090

[12] Hudelist G, Fritzer N, Thomas A et al. Diagnostic delay for endometriosis in Austria and Germany: causes and possible consequences. Hum Reprod 2012; 27: 3412-3416. doi:10.1093/humrep/des316

[13] Staal AHJ, Van Der Zanden M, Nap AW. Diagnostic Delay of Endometriosis in the Netherlands. Gynecol Obstet Invest 2016; 81: 321-324. doi: $10.1159 / 000441911$

[14] Kreuzer VK, Kimmel M, Schiffner J et al. Possible Reasons for Discontinuation of Therapy: an Analysis of 571071 Treatment Cycles From the German IVF Registry. Geburtsh Frauenheilk 2018; 78: 984-990. doi:10.1055/a-0715-2654

[15] du Bois A, Rochon ], Lamparter $C$ et al. [Impact of center characteristics on outcome in ovarian cancer in Germany]. Zentralbl Gynakol 2005; 127: 18-30. doi:10.1055/s-2005-836290

[16] du Bois A, Rochon J, Lamparter C et al. [The Quality Assurance Program of the AGO Organkommission OVAR (QS-OVAR): Pattern of Care and Reality in Germany 2001]. Zentralbl Gynakol 2005; 127: 9-17. doi:10.1055/s-2005-836289

[17] Munoz KA, Harlan LC, Trimble EL. Patterns of care for women with ovarian cancer in the United States. J Clin Oncol 1997; 15: 3408-3415. doi:10.1200/JCO.1997.15.11.3408

[18] Schweppe KW, Ebert AD, Kiesel L. Endometriosezentren und Qualitätsmanagement. Gynakologe 2010; 43: 233-240. doi:10.1007/s00129009-2484-x

[19] Burghaus S, Hildebrandt T, Fahlbusch C et al. Standards Used by a Clinical and Scientific Endometriosis Center for the Diagnosis and Therapy of Patients with Endometriosis. Geburtsh Frauenheilk 2019; 79: 487-497. doi:10.1055/a-0813-4411

[20] Zalewski M, Zeppernick F, Wölfler MM et al. Pattern of Endometriosis Care in German-speaking Countries: the QS ENDO Project. J Reproduktionsmed Endokrinol 2017; 14: 311-312

[21] Canis M, Donnez JG, Guzick DS et al. Revised American Society for Reproductive Medicine classification of endometriosis: 1996. Fertil Steril 1997; 67: 817-821. doi:10.1016/S0015-0282(97)81391-X

[22] Tuttlies F, Keckstein J, Ulrich $U$ et al. [ENZIAN-score, a classification of deep infiltrating endometriosis]. Zentralbl Gynakol 2005; 127: 275281. doi:10.1055/s-2005-836904

[23] Facchin F, Barbara G, Saita E et al. Impact of endometriosis on quality of life and mental health: pelvic pain makes the difference. J Psychosom Obstet Gynaecol 2015; 36: 135-141. doi:10.3109/ 0167482X.2015.1074173

[24] Soriano D, Schonman R, Nadu A et al. Multidisciplinary Team Approach to Management of Severe Endometriosis Affecting the Ureter: Longterm Outcome Data and Treatment Algorithm. J Minim Invasive Gynecol 2011; 18: 483-488. doi:10.1016/j.jmig.2011.04.011

[25] Langebrekke A, Qvigstad E. Ureteral endometriosis and loss of renal function: Mechanisms and interpretations. Acta Obstet Gynecol Scand 2011; 90: 1164-1166. doi:10.1111/j.1600-0412.2011.01210.x 